\title{
Effect of Prepreg Cut on the Mechanical Properties in CFRP Laminates*
}

\author{
Hayato NAKATANI**, Kenji NAKAYA***, Akira MATSUBA****, \\ Yousuke KOUNO**** and Shinji OGIHARA** \\ ** Faculty of Science and Technology, Tokyo University of Science \\ 2641 Yamazaki, Noda, Chiba 278-8510, Japan \\ E-mail:hayatonakatani@rs.tus.ac.jp \\ ${ }^{* * *}$ Graduate School of Science and Technology, Tokyo University of Science \\ **** West Region Industrial Research Center, Hiroshima Prefectural Technology Research Institute \\ 2-10-1 Agaminami, Kure, Hiroshima 737-0004, Japan
}

\begin{abstract}
This paper investigates the effect of the fiber discontinuity, caused by the prepreg cut in fabricating laminated structures, on the mechanical properties in CFRP laminates. Stress-strain relations under tensile loadings are obtained for unidirectional laminates that contain the fiber discontinuity, and damages in the laminates have also been observed. Nonlinear stress-strain relations at the center of the laminates have been found to be due to the interfacial debonding at discontinuous edge. In addition, it has been revealed that strains at distant from the fiber discontinuity increase sharply because the interlaminar shear stress is released by the interlaminar delamination that grows from the discontinuity. Finite element (FE) analysis model has been developed in order to calculate the stress distribution in the plates. The FE results have shown that stress concentrates in the fiber discontinuous edge with thicker discontinuous layer. Furthermore, shear-lag analysis model has also been proposed, and it has been shown that obtained stress distributions agree well qualitatively with the FE results.
\end{abstract}

Key words: CFRP Laminates, Fiber Discontinuity, Mechanical Property, Debonding, Delamination, Finite Element Method, Shear-Lag Analysis

\section{Introduction}

It is well known that fiber reinforced composites have not only high strength and light weight characteristics but also various functions that are not exhibited by homogeneous materials. Especially carbon fiber reinforced polymers (CFRP) have been applied to aerospace structure due to their high specific strength and stiffness, and are expected to be used in general industrial machinery such as automobiles in the near future.

One of the important issues about the application of CFRP is manufacturing costs. It is an unavoidable problem that fragments of the materials are remained when complicated composite laminate structures are manufactured by using prepregs. In order to improve the materials costs, disposal of the fragments of prepregs must be minimized. To deal with this problem, prepreg tapes are coming into use because they produce fewer fragments compared to ordinary prepreg sheets. Furthermore, fiber orientation in the laminates is optimized by this material with narrow width. With the prepreg tapes, however, there must be seams in the laminates. These seams, that are fiber discontinuities, will contribute to the stress concentration and lead to the initiation of damages and strength reduction. These fiber discontinuities can be included in the complicated laminated structures made by the

${ }^{*}$ Received 7 July, 2011 (№. 11-0385) [DOI: 10.1299/jmmp.5.742]

Copyright (C) 2011 by JSME 
ordinary prepreg sheets. Several studies have introduced the ply drop-off or terminated plies for thickness-tapered composite laminates. For instance, Wisnom and Jones ${ }^{(1)}$ investigated interaction between curvature induced interalaminar tensile stresses and stresses arisen at terminated plies for curved specimens under bending load. Hélénon et al. developed finite element model for assessment of criticality of high localized stress concentrations for mode II using a unidirectional specimen with cut central plies ${ }^{(2)}$. A mixed variational formulation for interlaminar stress prediction of laminates that taper in thickness was developed by Harrison and Johnson ${ }^{(3)}$. Failure mechanisms of composite coupon specimens and components with multiple inter ply drop steps were investigated by Fish et al. ${ }^{(4)}$ and Vizzini et al. ${ }^{(5)}$ Her employed a combination of analytical and numerical method to solve the singular stress field in the ply drop-off problem ${ }^{(6)}$. He et al. proposed a stress analysis model of the unidirectional laminates with drop-off plies in tension to obtain interlaminar stress ${ }^{(7)}$. However, there are few papers available that give basic investigation against the effect of the prepreg cut on mechanical properties of the composite laminates so far. This paper aims to reveal the effect of prepreg cut (fiber discontinuity) on the mechanical properties in the CFRP laminates by using laminates with seams of the prepregs.

\section{Materials and Experimental Methods}

\subsection{Laminates with Fiber Discontinuity and Tensile Tests}

Unidirectional laminates using T700SC/2592 (Toray Industries, Inc.) carbon/epoxy prepregs with stacking sequence of $\left[0_{8}\right]$ were used. To introduce the fiber discontinuities in the laminates, two cut prepregs were placed next to each other in fiber direction in the same layer as gap between the prepregs was kept minimum. Five types of the laminates with different fiber discontinuity thickness were prepared; the laminate (a) without fiber discontinuity (normal unidirectional laminate), that with (b) 2-ply, (c) 4-ply, (d) 6-ply thick fiber discontinuity in the center of the laminate, and (e) that with 8-ply (all) cut prepregs. Figure 1 shows the schematic of these laminates. It should be noted that there was resin rich region at the fiber discontinuity.

Specimens for tensile tests were $200 \mathrm{~mm}$ length $\times 10 \mathrm{~mm}$ width coupon with $1.2 \mathrm{~mm}$ thick, and $50 \mathrm{~mm}$ from each end was clamped by the grip. Tensile tests were conducted by universal testing machine (TENSILON RTF-1350, A\&D Company, Limited) under crosshead speed of $1.0 \mathrm{~mm} / \mathrm{min}$. As shown in Fig.2, biaxial strain gages with $2 \mathrm{~mm}$ gage length were put on the center of the specimen which is just above fiber discontinuity (Fig.2 (a)) and on $20 \mathrm{~mm}$ distant from the center (Fig.2 (b)). For 6-ply discontinuity specimens, the edge face was also observed with an optical microscope. The tensile loading was paused and then images of the edge face were obtained. For this case, uniaxial strain gages with
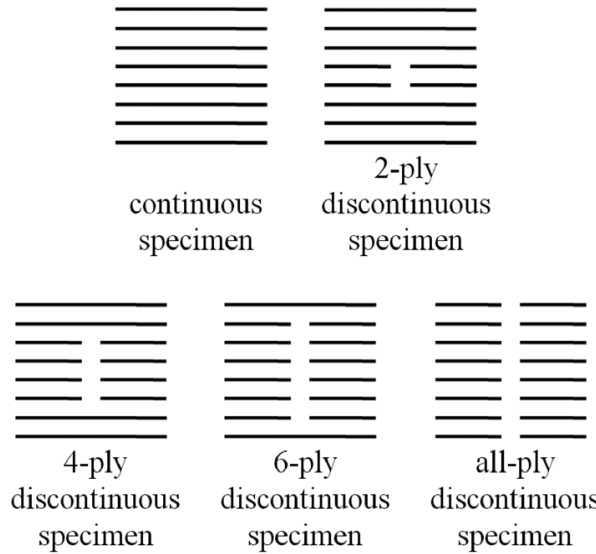

Fig.1 Schematic of the laminates with prepreg cut. 
(a)

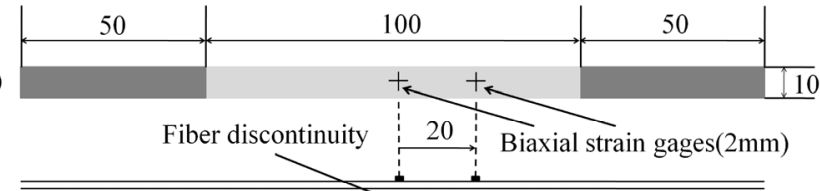

(b)

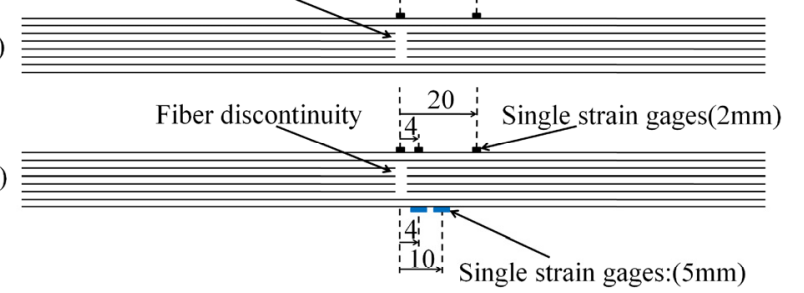

Unit:mm

Fig.2 Schematic of the tensile specimen used in this study.

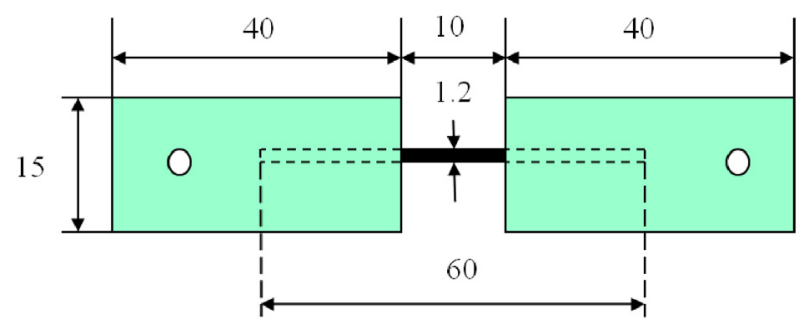

Fig.3 Dimensions of specimen for microscopic tensile tests.

$2 \mathrm{~mm}$ or $5 \mathrm{~mm}$ gage length were used as shown in Fig.2(c).

\subsection{Microscopic Tensile Tests}

In order to obtain detailed observation of damage initiation and damage growth in the laminates during tensile loading, tensile tests were conducted by a small loading equipment which was attached onto the optical microscope (referred as the microscopic tensile tests). The laminates were cut into $60 \mathrm{~mm}$ length $\times 3 \mathrm{~mm}$ width coupon and GFRP tabs were adhered, and then holes of $3 \mathrm{~mm}$ in diameter were drilled in the tabs for the pin joint with the loading equipment as shown in Fig.3. Maximum load of the load cell was $2000 \mathrm{~N}$, and tensile speed was $0.5 \mathrm{~mm} / \mathrm{min}$. The edge face of the specimen was polished so as to obtain better microscopic images. Note that the width direction of the laminates is perpendicular to the paper plane in Fig.3 because of the configuration of the test equipment.

\section{Analysis}

\subsection{Model for Finite Element Method}

From the symmetric properties of the specimen, one eighth of the laminates were modeled by using 3-dimensional solid elements as shown in Fig.4. The resin rich region at the fiber discontinuity was modeled as rectangular part with measured length and thickness of discontinuous layer. Measured values of this length for each specimen are shown in Table 1. Orthotropic elasticity was applied for the unidirectional CFRP plies. Table 2 presents material properties used in this analysis obtained experimentally. As a tensile condition, displacement was applied to the right edge in the figure so that overall strain in $X$ direction to be $1 \%$. These modeling and calculation were carried out by commercial finite element code ABAQUS. 


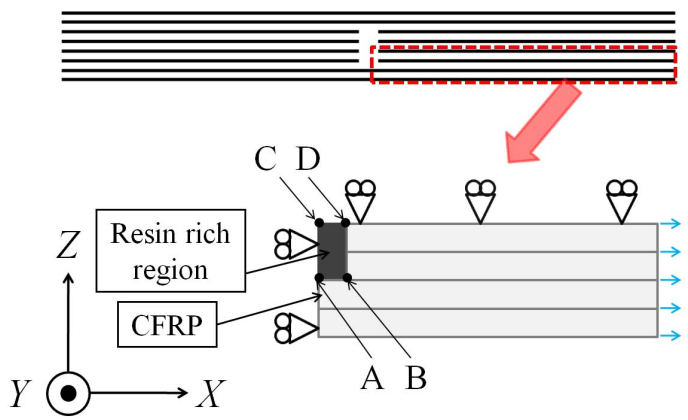

Fig.4 Finite element model of the laminates with 4-ply discontinuous layer.

Table 1 Length of the resin rich region in $X$ direction.

\begin{tabular}{c|c}
\hline Number of discontinuous plies & Length of the resin rich region $(\mathrm{mm})$ \\
\hline 2-ply & 0.020 \\
\hline 4-ply & 0.027 \\
\hline 6-ply & 0.043 \\
\hline
\end{tabular}

Table 2 Material properties used in the finite element analysis.

\begin{tabular}{c|c|c|c|c|c|c|c}
\hline \multicolumn{6}{c|}{ CFRP } & \multicolumn{2}{c}{ Resin } \\
\hline $\begin{array}{c}E_{X} \\
(\mathrm{GPa})\end{array}$ & $\begin{array}{c}E_{Y}=E_{Z} \\
(\mathrm{GPa})\end{array}$ & $\begin{array}{c}G_{X Y}=G_{X Z} \\
(\mathrm{GPa})\end{array}$ & $\begin{array}{c}G_{Y Z} \\
(\mathrm{GPa})\end{array}$ & $v_{X Y}=v_{X Z}$ & $v_{Y Z}$ & $\begin{array}{c}E \\
(\mathrm{GPa})\end{array}$ & $v$ \\
\hline 130 & 9.53 & 4.73 & 3.18 & 0.34 & 0.5 & 3.0 & 0.3 \\
\hline
\end{tabular}

\subsection{Shear-Lag Model}

Shear-lag analysis was also conducted for a quarter of the laminates in 2-dimension. Figure 5 shows the shear-lag model proposed in this study. As can be seen in the figure, $l$ and $L$ are length of the resin rich region and continuous layer in $x$ direction, $t_{1}$ and $t_{2}$ are thicknesses of the continuous and discontinuous layer, respectively. For $0<x<l$, which is subscripted as " $r$ " (resin rich), force equilibrium between the resin rich region and the continuous layer as shown in Fig.6 can be written as

$$
\begin{aligned}
& t_{1} \frac{d \sigma_{1}}{d x}=\tau \\
& t_{2} \frac{d \sigma_{2}}{d x}=-\tau
\end{aligned}
$$

where, $\sigma$ is stress in $x$ direction, $\tau$ is shear stress and subscripts 1 and 2 denote for the continuous and the discontinuous layer, respectively. Now the shear stress $\tau$ is assumed to be defined as

$$
\tau=k_{r}\left(u_{1}^{r}-u_{2}^{r}\right)
$$

where $u$ is the displacement in $x$ direction and $k_{r}$ is constant. Summation of Eq. (1) and Eq. (2) with substitution of Eq. (3) yields

$$
\frac{d^{2}}{d x^{2}}\left(u_{1}^{r}-u_{2}^{r}\right)=\left(\frac{1}{t_{1} E_{1}}+\frac{1}{t_{2} E_{r}}\right) k_{r}\left(u_{1}^{r}-u_{2}^{r}\right)
$$

where $E$ is the Young's modulus. Integrating Eq. (4), we obtain

$$
u_{1}^{r}-u_{2}^{r}=A e^{\sqrt{\alpha_{r} k_{r}} x}+B e^{-\sqrt{\alpha_{r} k_{r}} x}
$$

with 


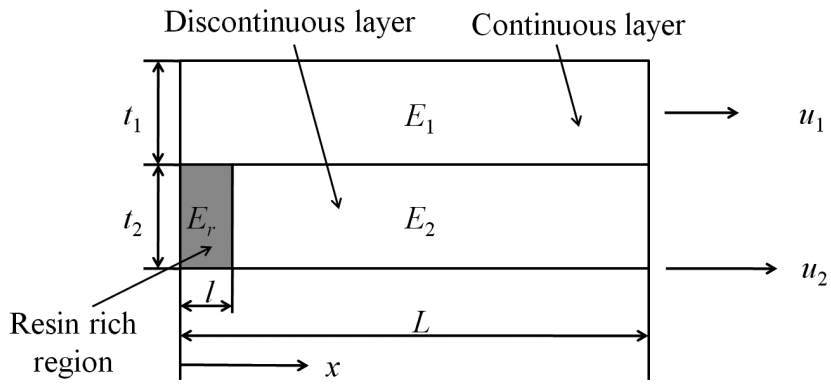

Fig.5 The shear-lag model proposed in this study.

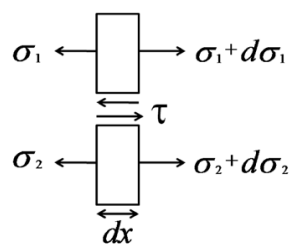

Fig.6 Force equilibrium between the resin rich region and the continuous layer

$$
\alpha_{r}=\frac{1}{t_{1} E_{1}}+\frac{1}{t_{2} E_{r}}
$$

where $A$ and $B$ are integration constants that are determined from continuity conditions. Force equilibrium in the entire model can be written as

$$
t_{1} E_{1} \frac{d u_{1}^{r}}{d x}+t_{2} E_{r} \frac{d u_{2}^{r}}{d x}=\sigma\left(t_{1}+t_{2}\right)
$$

where $\sigma$ is the applied stress. The overall displacement is assumed to be equal to the sum of that of continuous and discontinuous layers then,

$$
u_{1}^{r}-u_{2}^{r}=\left(\frac{1}{G_{1}} \frac{t_{1}}{2}+\frac{1}{G_{r}} t_{2}\right) \tau
$$

where $G$ is the shear modulus. From the comparison of Eq. (3) and Eq. (8), we obtain

$$
k_{r}=\frac{2 G_{1} G_{r}}{t_{1} G_{r}+2 t_{2} G_{1}} .
$$

For $l<x<L$, which is subscripted as " $c$ " (continuous), in the same manner as described above we can obtain

$$
\begin{aligned}
& u_{1}^{c}-u_{2}^{c}=C e^{\sqrt{\alpha_{c} k_{c}} x}+D e^{-\sqrt{\alpha_{c} k_{c}} x} \\
& \alpha_{c}=\frac{1}{t_{1} E_{1}}+\frac{1}{t_{2} E_{2}} \\
& t_{1} E_{1} \frac{d u_{1}^{c}}{d x}+t_{2} E_{2} \frac{d u_{2}^{c}}{d x}=\sigma\left(t_{1}+t_{2}\right) \\
& k_{c}=\frac{2 G_{1} G_{2}}{t_{1} G_{2}+2 t_{2} G_{1}}
\end{aligned}
$$

where $C$ and $D$ are integration constants. The continuity conditions for displacements and stresses are

$$
\begin{aligned}
& u_{1}^{r}=u_{2}^{r}=0 \quad(x=0) \\
& u_{1}^{r}=u_{1}^{c}, u_{2}^{r}=u_{2}^{c}, \sigma_{1}^{r}=\sigma_{1}^{c}, \sigma_{2}^{r}=\sigma_{2}^{c} \quad(x=l) \\
& u_{1}^{c}=u_{2}^{c}=\varepsilon L \quad(x=L)
\end{aligned}
$$


Table 3 Material properties used in the shear-lag analysis.

\begin{tabular}{c|c}
\hline Continuous ply & $E_{1}=130(\mathrm{GPa}), G_{1}=4.73(\mathrm{GPa})$ \\
\hline Discontinuous ply & $E_{2}=130(\mathrm{GPa}), G_{2}=4.73(\mathrm{GPa})$ \\
\hline Resin rich region & $E_{\mathrm{r}}=3.0(\mathrm{GPa}), G_{\mathrm{r}}=1.2(\mathrm{GPa})$ \\
\hline
\end{tabular}

Table 4 Size of the shear-lag model.

\begin{tabular}{c|c|c|c}
\hline Number of discontinuous plies & $t_{1}(\mathrm{~mm})$ & $t_{2}(\mathrm{~mm})$ & $l(\mathrm{~mm})$ \\
\hline 2-ply & 0.45 & 0.15 & 0.020 \\
\hline 4-ply & 0.30 & 0.30 & 0.027 \\
\hline 6-ply & 0.15 & 0.45 & 0.043 \\
\hline
\end{tabular}

where $\varepsilon$ is overall strain in the model. From Eqs. (5) to (14) we can obtain the displacements $u_{1}^{r}, u_{2}^{r}, u_{1}^{c}$ and $u_{2}^{c}$. From these displacements, stress in each layer is given as

$$
\sigma_{i}^{p}=\frac{d u_{i}^{p}}{d x} E_{j} \quad\left(\begin{array}{l}
p=r, c \\
i=1,2 \\
j=r \text { if } p=r \text { and } i=2 ; \text { otherwise } j=i
\end{array}\right) .
$$

Material properties used in this analysis are presented in Table 3. Each size of the shear-lag model is shown in Table 4. $L=100 \mathrm{~mm}$ for any case. As well as the FE model, displacement was applied to the right edge so that overall strain in $x$ direction to be $1 \%$.

\section{Results and Discussion}

\subsection{Tensile tests}

Figure 7 shows the stress-strain curves of the laminates with or without the fiber discontinuity obtained by the tensile tests. As for the laminates that contains both continuous and discontinuous layer (Fig.7 (b), (c) and (d)), strains 20mm distant from the fiber discontinuity increased linearly until certain stresses. Shortly after that, however, the strains increased sharply, and linear relations followed again. The strains just above the fiber discontinuity showed nonlinear stress-strain relations at low stress level. In addition, these two strains agreed each other after the sharp increase of strains $20 \mathrm{~mm}$ distant from fiber discontinuity. Table 5 represents the stress and longitudinal strain of the laminates at the onset of the discontinuous behavior as seen in Fig.7. It should be noted that lower overall stress was required to show the discontinuous stress-strain behavior with thicker discontinuous layers

Figure 8 shows the stress-strain curves of the laminates with 6-ply thick fiber discontinuity with five strain gages. Images of the edge faces during the tensile loading were shown in Fig.9. As indicated as " $\mathrm{A}$ " in Fig.8, strain just above the fiber discontinuity began to show nonlinearity after the stress came up to about $100 \mathrm{MPa}$. This corresponds to the initiation of interfacial debonding between the resin rich region and fiber edge of the fiber discontinuity as shown in Fig.9(a). The strains $4 \mathrm{~mm}, 10 \mathrm{~mm}$ and $20 \mathrm{~mm}$ distant from the fiber discontinuity showed sharp increase as indicated "B" in Fig.8, and these behaviors are the same as seen in Fig.7 (b)-(d). It is considered that interlaminar delamination between continuous and discontinuous layers (Fig.9 (b)) attributed the sharp increase of the strains. Note that the delamination length was measured to be approximately $5 \mathrm{~mm}$ from the fiber discontinuity in loading direction.

\subsection{Microscopic Tensile Tests}

Figure 10 presents images of the edge face of the laminates with 4-ply thick fiber discontinuity during the microscopic tensile tests with stress of (a) $583 \mathrm{MPa}$ and (b) $712 \mathrm{MPa}$. 


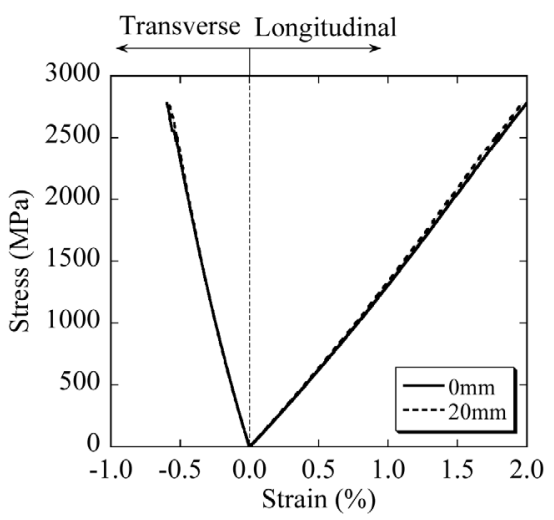

(a) 0-ply discontinuous specimen

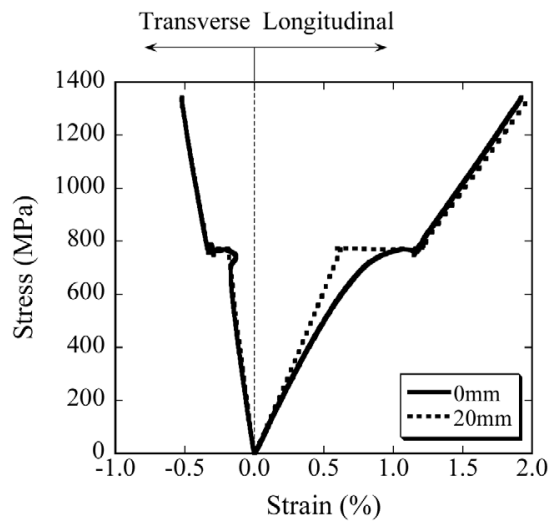

(c) 4-ply discontinuous specimen

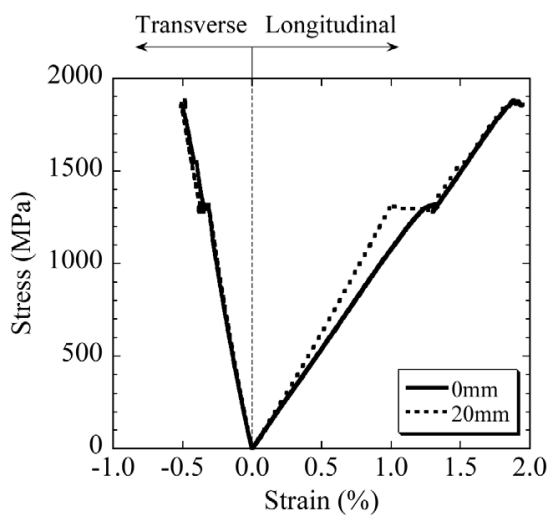

(b) 2-ply discontinuous specimen

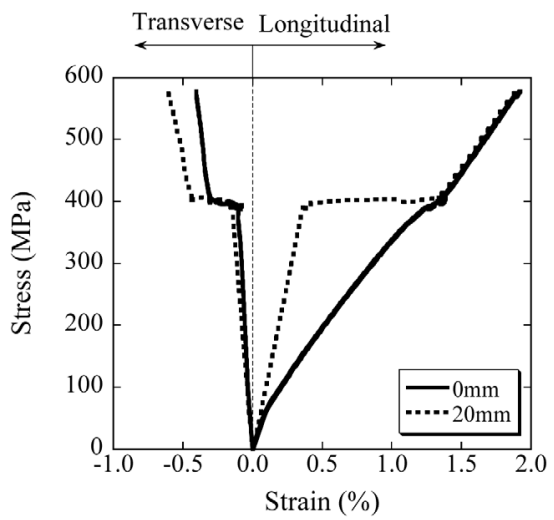

(d) 6-ply discontinuous specimen

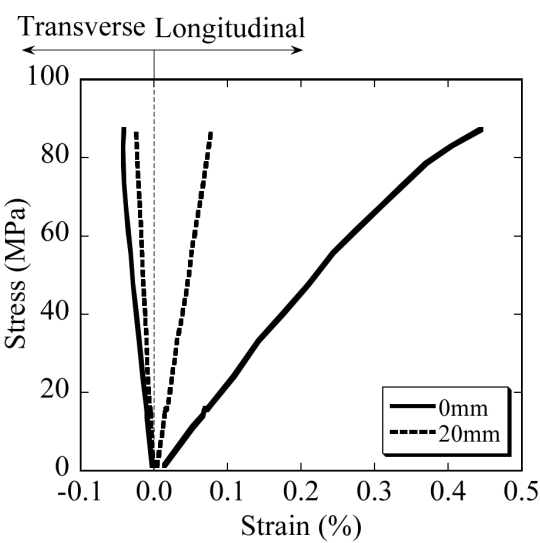

(e) 8(all)-ply discontinuous specimen

Fig.7 Stress-strain curves of the CFRP laminates with fiber discontinuity.

Table 5 Average stress and longitudinal strain of the CFRP laminates with fiber discontinuity at onset of the discontinuous behavior and at fracture.

\begin{tabular}{c|c|c|c}
\hline $\begin{array}{c}\text { Number of } \\
\text { discontinuous plies }\end{array}$ & $\begin{array}{c}\text { Stress and strain at onset of } \\
\text { discontinuous behavior } \\
(\mathrm{MPa}) /(\%)\end{array}$ & $\begin{array}{c}\text { Fracture } \\
\text { stress (MPa) }\end{array}$ & $\begin{array}{c}\text { Fracture strain (\%) } \\
\text { at 0mm / 20mm } \\
\text { distant from the fiber } \\
\text { discontinuity }\end{array}$ \\
\hline 0-ply & --- & 2770 & $2.02 / 2.00$ \\
\hline 2-ply & $1300 / 1.07$ & 1910 & $1.94 / 1.94$, \\
\hline 4-ply & $773 / 0.65$ & 1340 & $1.92 / 1.93$ \\
\hline 6-ply & $398 / 0.45$ & 550 & $1.89 / 1.88$ \\
\hline 8(all)-ply & --- & 80 & $0.38 / 0.068$ \\
\hline
\end{tabular}




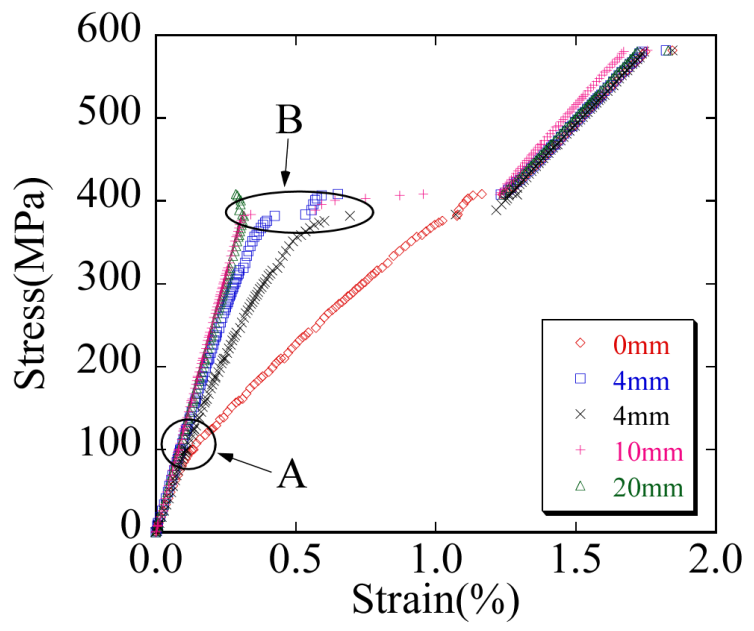

Fig.8 Stress-strain curves of 6-ply discontinuous specimen.

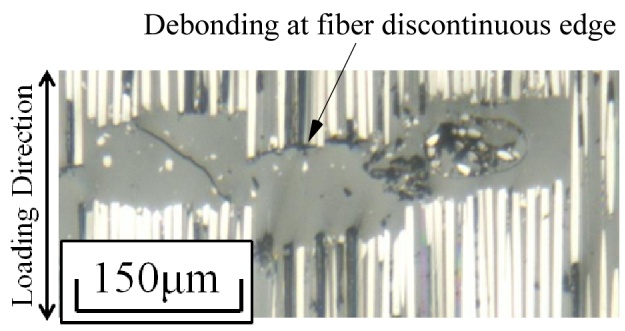

(a) $98 \mathrm{MPa}$

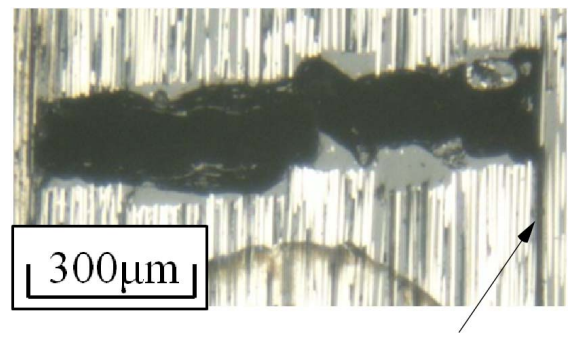

Interlaminar delamination between continuous and discontinuous plies

(b) $384 \mathrm{MPa}$

Fig.9 Damages around the fiber discontinuity in the 6-ply discontinuous specimen.

From Fig.10 (a), it was found that the fracture in resin rich region was followed by the interlaminar delamination. The delamination had just begun to grow in this instant as seen in the figure. It was confirmed that extensive delamination was presented in the laminates at $712 \mathrm{MPa}$ as shown in Fig.10 (b). Since interlaminar shear stress was released by the delamination, the strains at two different positions agreed with each other at more than about 800MPa as seen Fig.7 (c).

\subsection{Finite Element Analysis}

The stress distribution on upper side line that starts from point $\mathrm{C}$ and pass through point D in $X$ direction in Fig.4 was shown in Fig.11. In this figure, stress was normalized by applied overall stress, and the horizontal axis represents the distance from center of the specimen (point $\mathrm{C}$ in Fig.4). From this figure, it was found that the normalized stress at the interface (point D in Fig.4) increased with the thickness of the fiber discontinuous layer. Here, positions of the point $\mathrm{D}$ are equal to the length of the resin rich region presented in Table 2. When the interfacial debonding is assumed to initiate with a certain threshold 


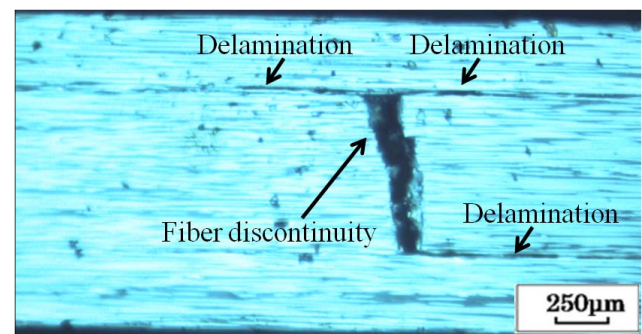

(a) $583 \mathrm{MPa}$

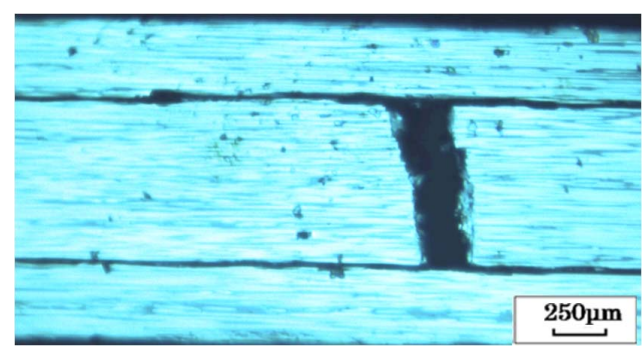

(b) $712 \mathrm{MPa}$

Fig.10 Damages around the fiber discontinuity in the 4-ply discontinuous specimen.

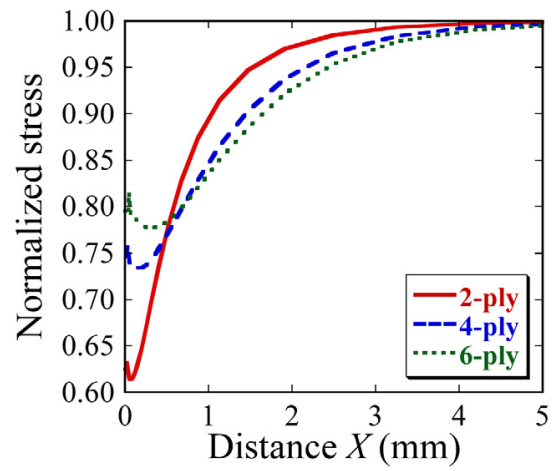

Fig.11 Normalized stress in $X$ direction in the laminates with 2, 4 and 6-ply fiber discontinuity.

tensile stress at the interface, this result corresponds to the experimental results where lower overall stress was required to initiate the debonding with thicker discontinuous layers as seen in Table 5.

Figure 12 shows the interlaminar shear stress $\tau_{X Y}$ between the continuous and discontinuous layers. The distance from center of the specimen (point A in Fig.4) was taken as a horizontal axis. The shear stress increased with the distance from the center, and dropped to almost zero at the interface. It was also confirmed that the shear stress increased to higher value with thicker discontinuous layers. Apparently the initiation of the interlaminar delamination is affected by the shear stress. Therefore, results obtained by the FE analyses qualitatively explain the experimental results where stress levels at which discontinuous behaviors were shown decreased with thicker discontinuous layers.

\subsection{Shear-Lag Analysis}

Figure 13 shows the comparison of the stress distributions between shear-lag and FE results of with (a) 2-ply, (b) 4-ply and (c) 6-ply discontinuous layer. The longitudinal axis represents the stress normalized by applied overall stress in the model. The normalized stress obtained by each analysis agreed well, and was confirmed to approach 1 with the distance from the resin rich region. As well as the FE analysis, the results of shear-lag 


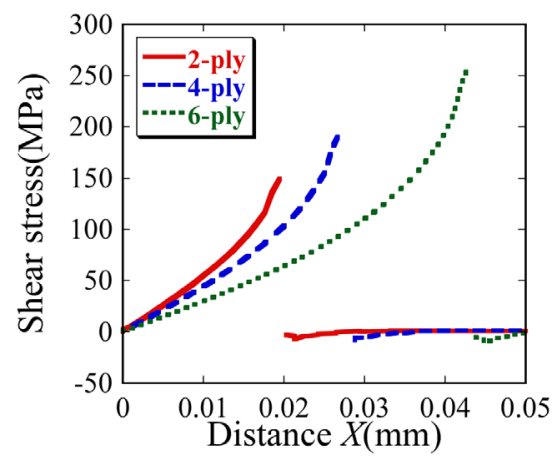

Fig.12 Normalized interlaminar shear stress along the interface between the continuous and discontinuous plies.

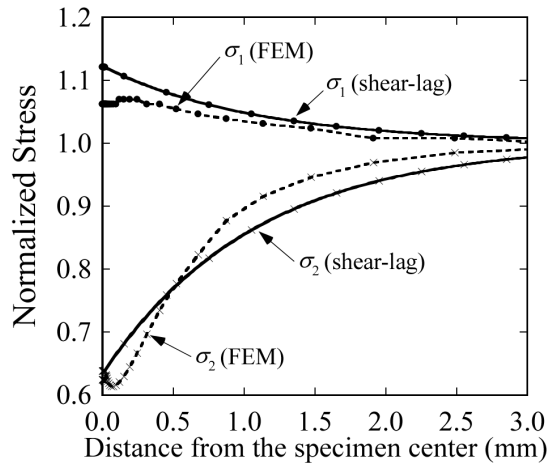

(a) 2-ply discontinuous specimen

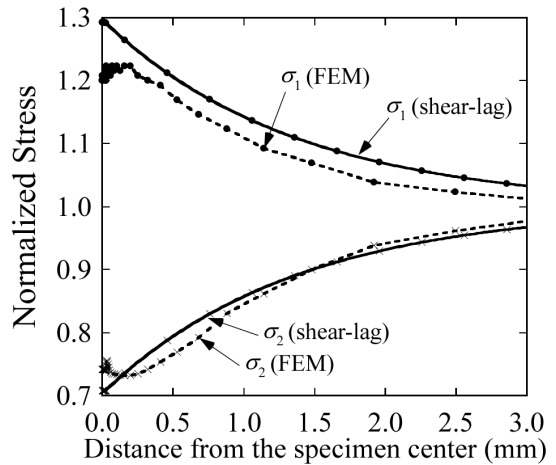

(b) 4-ply discontinuous specimen

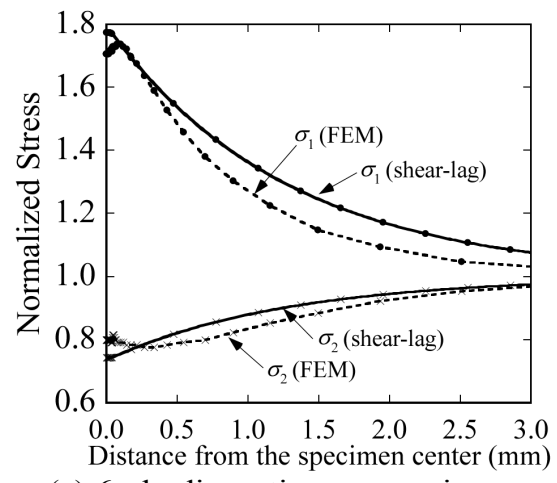

(c) 6-ply discontinuous specimen

Fig.13 Comparison of the normalized stress distribution between shear-lag and finite element results.

analysis also explain the experimental evidence that lower overall stress was required to initiate the debonding with thicker discontinuous layers since the stress at the interface resulted in a higher value. From these comparisons, it was concluded that the shear-lag model proposed in this study represents the reasonable value of the stress in the laminates.

\section{Conclusion}

Experimental and analytical investigations were conducted in order to obtain basic understandings against the effect of the fiber discontinuity on the mechanical properties in the composite laminates. Tensile tests and damage observation were conducted on the unidirectional laminates with prepreg cutout. From these results it was found that nonlinear behavior of the strain just above the fiber discontinuity corresponds to the initiation of the 
interfacial debonding at the discontinuity edge. Likewise the interlaminar delamination that grew from the discontinuity edge was found to induce the sharp increase in the strain at the distance from the fiber discontinuity. In addition, lower overall stress was required to initiate the debonding and interlaminar delamination with thicker discontinuous layers. Furthermore, stress analyses were carried out by finite element method and shear-lag model proposed in this work, and obtained stress distributions showed qualitative agreement.

\section{References}

1. Wisnom, M.R. and Jones, M.I., Delamination due to interaction between curvature induced interlaminar tension and stresses at terminating plies, Composite Structures, Vol. 32 (1995), pp. 615-620.

2. Hélénon, F., Wisnom, M.R., Hallett, S.R. and Allegri, G., An approach for dealing with high local stresses in finite element analyses, Composites: Part A, Vol. 41 (2010), pp. 1156-1163.

3. Harrison, P.N. and Johnson, E.R., A mixed variational formulation for interlaminar stresses in thickness-tapered composite laminates, International Journal of Solids Structures, Vol. 33 (1996), pp. 2377-2399.

4. Fish, J.C. and Lee, S.W., Delamination of tapered composite structures, Engineering Fracture Mechanics, Vol. 34 (1989), pp. 43-54.

5. Vizzini, A.J. and Lee, S.W., Damage analysis of composite tapered beams, Journal of American Helicopter Society, Vol. 40 (1995), pp. 43-49.

6. Her, S.-C., Stress analysis of ply drop-off in composite structures, Composite Structures, Vol. 57 (2002), pp. 235-244.

7. He, K., Ganesan, R. and Hoa, S.V., Modified shear-lag model for analysis of a composite laminate with drop-off plies, Composites Science and Technology, Vol. 63 (2003), pp. 1453-1462. 